\title{
Safer Margins for Option Trading: How Accuracy Promotes Efficiency
}

\author{
Rafi Eldor \\ Interdisciplinary Center, Israel \\ Shmuel Hauser \\ Ono Acdemic College and Ben-Gurion University, Israel \\ Uzi Yaari* \\ Rutgers University, USA
}

\begin{abstract}
Margin requirements are designed to control the default risk inherent to commitments undertaken by traders writing options. Much like similar institutions, the Tel Aviv Stock Exchange first adopted a system based on the Standard Portfolio Analysis of Risk (SPAN), which sets required levels of options margin according to the most pessimistic of 16 possible outcomes. Seeking to lower the probability of default without adversely affecting liquidity, the Exchange switched in 2001 to a more detailed margin system based on the most pessimistic of 44 scenarios. This unique change provides an ideal laboratory for testing the impact of increased margining precision on the efficiency of option trading. Based on a sample of over 3 million transactions, this study demonstrates that the more accurate pricing of default risk over the studied range increases efficiency by a number of measures, including a smaller implied standard deviation and deviations from put-call parity. (JEL: G11, G13, G14, G20)
\end{abstract}

Keywords: option margins, option default risk, market efficiency, SPAN system

* Rafi Eldor is from the Interdisciplinary Center, Hertzlia, Israel; Shmuel Hauser is from Ono Acdemic College and Ben-Gurion University, Israel; and Uzi Yaari is from Rutgers University at Camden, NJ, USA. The authors thank Eric Berger, Menachem Brenner, Avi Kamara, Roni Michaeli, and Oded Sarig for their helpful comments, and Avi Suliman and Leon Sandler for their assistance in processing the data. The authors have further benefitted from the critical comments of an unknown referee.

(Multinational Finance Journal, 2011, vol. 15, no. 3/4, pp. 217-234)

(C) Multinational Finance Society, a nonprofit corporation. All rights reserved. DOI: $10.17578 / 15-3 / 4-3$ 


\section{Introduction}

Margin requirements limit the opportunity of traders to shift default risk to the exchange clearinghouse thereby promoting market efficiency through confidence in the financial integrity of traders and the institution behind them. Margin requirements are designed to control the default risk inherent to contractual commitments undertaken by option traders. Depending on the selected strategy, option trading may be exposed to a high credit risk due to the creation of a high-multiple leverage whereby a small price change in the underlying asset can induce a dramatic price change in the options themselves. The SPAN-16 margining method is designed to cope with that risk by accounting for trader liability exposure under 16 potential scenarios of different option trading strategies, including those of extreme financial risk.

The fate of SPAN-16 on the Tel Aviv Stock Exchange (TASE) took a unique course when experience suggested that, unlike stocks, the inherent exposure of option trading to a high leverage and related risk justifies a more accurate, more selective risk measurement. To this end, the margining method was modified from SPAN-16 to the more detailed SPAN-44. The increased number of scenarios, each of a narrower price interval within the same price range, had the potential of a greater pricing accuracy, which may or may not lead to a larger total margin. Assuming an insignificant change in the cost of pricing itself, this paper tests for a change in efficiency on the assumption that a greater margining precision will lower the clearinghouse risk of pricing errors by imparting to traders more accurate and consistent incentives in choosing the size of transaction, its price, and its strategy. In short, this study hypothesizes that SPAN-44 is more economic.

Earlier studies examine the impact of margins separately on markets of stocks and their derivatives. Following a comprehensive survey of theoretical models and empirical evidence, Kupiec (1998) describes earlier findings as contradictory and inconclusive. ${ }^{1}$ Some of those studies claim that margin requirements promote instability in stock trading; others conclude that margin requirements have no significant effects on the volatility of share prices or share trading volume. ${ }^{2}$ Those

1. See for example Kupiec [1998] and Kose et al. [1997], Garbade [1982], Chowdry and Nanda [1998], Schwert [1989], Salinger [1989], Kupiec [1989], Hsieh and Miller [1990], and Seguin and Jarrell [1993].

2. See Schwert [1989], Salinger [1989], Kupiec [1989], Hsieh and Miller [1990], and 
findings contradict Hardouvelis $(1988,1990)$ and Seguin (1990) who find that increased margin requirements lower stock price volatility and lessen price deviation from fundamental value. According to Hardouvelis (1990), margining can be a useful tool for controlling spurious market volatility produced by speculators.

The disparity between margin requirements on options and underlying assets can be explained by their different relationship to financial leverage. As put by Figlewski (1984), margin on a stock is a loan, while margin on a stock's derivative is a performance bond. According to Kupiec (1998), increased margin requirements on options can increase volatility in the underlying share prices. Empirical margining studies conducted respectively by Fishe et al. (1990), Kupiec (1993), Hardouvelis and Kim (1995), and Day and Lewis (1997) fail to establish a systematic relationship between required futures margins and asset liquidity or price volatility in futures contracts written on U.S. indices of stocks, cash market assets, metal contracts, and crude oil. In contrast, Moser (1992) finds a significant negative correlation between the level of derivative margins and share price volatility in Germany. Theoretically, higher margin requirements should adversely affect trading volume since traders incur higher transaction costs. Yet, Fishe and Goldberg (1986) find that trading volume increases along with margin requirements, possibly as a result of a lower default probability. ${ }^{3}$

Can those findings be reconciled? Kose et al. (1997) address some of the issues by theoretically treating the impact of margin requirements set on options and their underlying stocks on trading in both markets. Under the benchmark assumption of no margin requirement on options, traders are shown to be active in both markets with a propensity to prefer stocks. With the introduction of margins to options, their built-in financial leverage invites a larger position. These authors show that the change in trader behavior is contingent on the relative margins placed on stocks and their options. They propose that market efficiency can be improved by setting the margins either high or low in both markets. Intuitively, informed traders of limited resources prefer to exploit their comparative advantage in the stock market but would settle for options, which offer a greater financial leverage and require a lower margin.

Seguin and Jarrell [1993].

3. See also Hartzmak (1986) who finds no significant relationship between the two variables, whereas Dutt and Wein (2002) find that the effect of increased margin requirements on trading volume is indeed negative, but only after controlling for price risk. 
On July 1, 2001 the TASE modified its basis for calculating option margins by raising the number of identified risk scenarios from 16 to 44 in the hope that the greater accuracy of measuring default risk will lower the probability of default without adversely affecting liquidity. This unique event created a laboratory for assessing the incremental efficiency of increased margining accuracy. Findings presented in this study extend those of Kupiec and White (1996) who rely on simulation to compare the SPAN system with the older Regulation-T Margining employed in the U.S. They conclude that both systems provide adequate protection against default risk, even though required margins under SPAN tend to be lower. Unlike their study, this one provides both simulation and empirical assessments of the effects of increased margining accuracy on trading efficiency in a given SPAN system. This is done by estimating deviations from put-call parity and four additional indicators of efficiency - volatility of underlying asset prices, asymmetry in option pricing, trading volume, and bid-ask spread.

Findings presented in this study reveal that increased margining accuracy leads to increased efficiency as reflected by 1) a significantly lower implied price volatility and 2) smaller deviations from put-call price parity, but 3) no systematic decrease in trading volume or increase in bid-ask price spread - all this despite a frequently increased margin. The finding of no change in volume following the switch from SPAN-16 to SPAN-44 suggests that the narrower spread is caused by more efficient trading.

The remainder of this paper is organized as follows. Section 2 illustrates the principles underlying the SPAN-16 and SPAN-44 margining systems; Section 3 offers simulations aimed at defining the context of the empirical tests; Section 4 reports and analyzes the tests themselves; and Section 5 provides a summary and conclusions.

\section{SPAN Margining System}

Margin requirements are designed to ensure the contractual rights of option buyers. First introduced by the Chicago Mercantile Exchange (CME) in $1988,{ }^{4}$ the SPAN margining system is based on analysis of the client's portfolio risk. Previously the CME relied on analysis of the

4. SPAN is a registered trademark of the CME. For an extensive explanation of the SPAN margining system, see Kupiec (1994). 
individual option or its trading strategies (Sofianos [1988] and Kupiec and White [1996]). That system typically overstated the risk and required margin by failing to recognize the interaction of returns among various assets. The SPAN-16 system was adopted by the TASE in August 1993.

The main inputs of the SPAN system are the scan ranges of price and price volatility of the assets underlying the derivative. This empirical study focuses on European options written on the TA-25 stock price index (hereafter the Index) composed of 25 companies of largest capitalization on the Exchange. The Exchange sets a fixed scan range for the price and price volatility of the Index as measured by its standard deviation. The standard deviation of implied volatility is averaged across eight options that include two types (call and put), two conditions (in-the-money and out-of-the-money), and two maturity series (expiration within the coming month and the month that follows).

Under the SPAN-16 system, call and put values are calculated by applying the Black-Scholes (1973) model to 16 scenarios. Those scenarios are defined by positive and negative Index changes within a set price scan range of $16 \%$ (not to be confused with the 16 scenarios) with price intervals set at $1 / 3$ of this range, and a scan range of price volatility set at intervals of $1 / 5$ of the Index standard deviation. For example, at the Index price of 450 , the scan range is $72=(0.16) 450$ and each interval, representing a separate scenario, is $24=(1 / 3) 72$ in each direction. Required margins are calculated at each interval for two standard deviations, each of which representing a discrete scenario. Thus, if the standard deviation is $25 \%$, margin requirements are calculated for each price scenario under the assumption of a rising standard deviation $30 \%=25 \%+(1 / 5) 25 \%$ and a falling standard deviation $20 \%=25 \%-(1 / 5) 25 \%$. Two extreme cases of the sharpest price movements (twice the scan range for prices and their standard deviation) are also introduced. For those scenarios, only $35 \%$ of the option's theoretical value is applied to reflect a lower probability. This procedure accounts for deep-out-of-the-money options that would otherwise fall outside the scan range.

After setting the theoretical value of each of the options held by the client in each of the scenarios, the most pessimistic outcome is identified and used as a basis for setting the minimum margin that must be deposited with the clearinghouse broker. Appendix table A1 displays the scenarios calculated under SPAN-16.

Table 1 shows the calculation of margin requirements for a strategy 
TABLE 1. SPAN-16: Sample Calculation of Margin Requirements

\begin{tabular}{lccrrrr}
\hline Scenario & $\begin{array}{c}\text { TA-25 } \\
\text { Index }\end{array}$ & $\begin{array}{c}\text { Std. Dev. } \\
(\%)\end{array}$ & $\begin{array}{c}\text { "Short" } \\
\text { Call }(450)\end{array}$ & $\begin{array}{c}\text { "Long" } \\
\text { 2Call }(460)\end{array}$ & $\begin{array}{c}\text { "Short" } \\
\text { Call (470) }\end{array}$ & Total \\
\hline 1. & 450 & 30 & $-1,186$ & 1,504 & -448 & -130 \\
2. & 450 & 20 & -811 & 798 & -168 & -181 \\
3. & 474 & 30 & $-2,826$ & 4,166 & $-1,461$ & -121 \\
4. & 474 & 20 & $-2,605$ & 3,528 & $-1,077$ & -154 \\
5. & 426 & 30 & -313 & 324 & -78 & -67 \\
6. & 426 & 20 & -93 & 56 & -7 & -44 \\
7. & 498 & 30 & $-4,979$ & 8,112 & $-3,194$ & -61 \\
8. & 498 & 20 & $-4,922$ & 7,880 & $-2,991$ & -33 \\
9. & 402 & 30 & -43 & 34 & -6 & -15 \\
10. & 402 & 20 & -2 & 0 & 0 & -2 \\
11. & 522 & 30 & $-7,326$ & 12,626 & $-5,379$ & -19 \\
12. & 522 & 20 & $-7,318$ & 12,642 & $-5,327$ & -3 \\
13. & 378 & 30 & -2 & 2 & 0 & -0 \\
14. & 378 & 20 & 0 & 0 & 0 & 0 \\
15. & 594 & 50 & $-5,083$ & 9,473 & $-4,391$ & -1 \\
16. & 306 & 50 & 0 & 0 & 0 & 0 \\
\hline
\end{tabular}

Note: This comprehensive example illustrates the SPAN margining system using the following parameters: (1) TA-25 index -450 ; (2) scan range $-16 \%$; (3) TA-25 annual standard deviation $-25 \%$; (4) interest rate $-6 \%$ per annum; (5) days to option exercise -16 . The investor is assume to be short in two Calls $(450,470)$, and long in two Calls (460). For each scenario, the value of each option is calculated according to the B-S model. For scenarios 15 and 16, the B-S result is multiplied by 0.35 . Margin requirements are based on the option values of various scenarios. In this example, Scenario 2 represents the worse case, which determines the margin requirement of $\$ 181$.

involving a long position of two calls with a strike price of 460 , and a short position of two calls with strike prices of 450 and 470. After calculating the Black-Scholes value of the entire position using SPAN-16, the margin is set according to the least favorable Scenario 2, indicating a minimum collateral deposit of $\$ 181 .^{5}$

Of a similar structure, the modified SPAN-44 system defines 44 scenarios with measuring intervals of $1 / 10$ instead of the wider original intervals of $1 / 3$ under the fewer 16 scenarios. The scan range of the price Index and its volatility remains unchanged at $16 \%$ and $1 / 5$ of the standard deviation, respectively. See appendix table A2 for the calculation of scenarios under SPAN-44.

A comparison between appendix tables $\mathrm{A} 1$ and $\mathrm{A} 2$ show how the

5. This outcome is also presented in figure 1:1a (16 scenarios) below. 
change from SPAN-16 to SPAN-44 generated more precise results by dividing each scan range into smaller intervals between scenarios, each of which has unique margin requirements. Some of the scenarios overlap: SPAN-16 scenarios 1, 2, 11, 12, 13, 14, 15, and 16 in table A1 are, respectively, identical to SPAN-44 scenarios 1, 2, 39, 40, 41, 42, 43 , and 44 in table A2.

\section{Margining Precision and Margin Levels: A Simulation}

Using simulation based on transaction data, this section explores effects of changing the margining systems on margin levels for three option strategies - "Butterfly," "Condor," and a combination of three call options, two written at strike price $X$ and one purchased at strike price $\mathrm{Y}$ where $\mathrm{Y}>\mathrm{X}$. The simulation is carried out in two stages. In the first stage, two opposite cases are sampled under each strategy - one in which the margin requirements of SPAN-44 are higher than those of SPAN-16, and one in which the reverse is true. In both cases, a standard deviation of $23 \%$ with an annual interest rate of $6 \%$ are assumed to hold at various Index prices. These strategies were selected for their sensitivity to margin requirements. Specifically, the SPAN method takes into account only options held in the investor's portfolio, ignoring holdings of the underlying real asset. Consistently, if the investor sells a Call or a Put option, the required margin is based on the extreme scenario. As shown in table 1, this is not an informative case since the extreme scenarios under SPAN-16 and SPAN-44 are similar. Likewise, a Covered Call and a Protective Put associated with a purchase or sale of the underlying asset have no effect on the margin calculation under the two methods. In the same vein, the sale of a Straddle is not an interesting case because the required margin is based on the extreme scenario of a Short Call or a Short Put. Only in a complex strategy, such as Butterfly, the required margin under SPAN-44 can vary from that under SPAN-16.

Results are displayed in figure 1 by six graphs, each incorporating observations from all scenarios under both systems. Graphs 1a, 1c, and 1e offer examples in which the required margin of SPAN-44 is greater than that of SPAN-16; graphs 1b, 1d, and 1f offer examples of the opposite margin relationship. These examples provide initial evidence that SPAN-44 is a more precise margining method, a conclusion further examined below. 

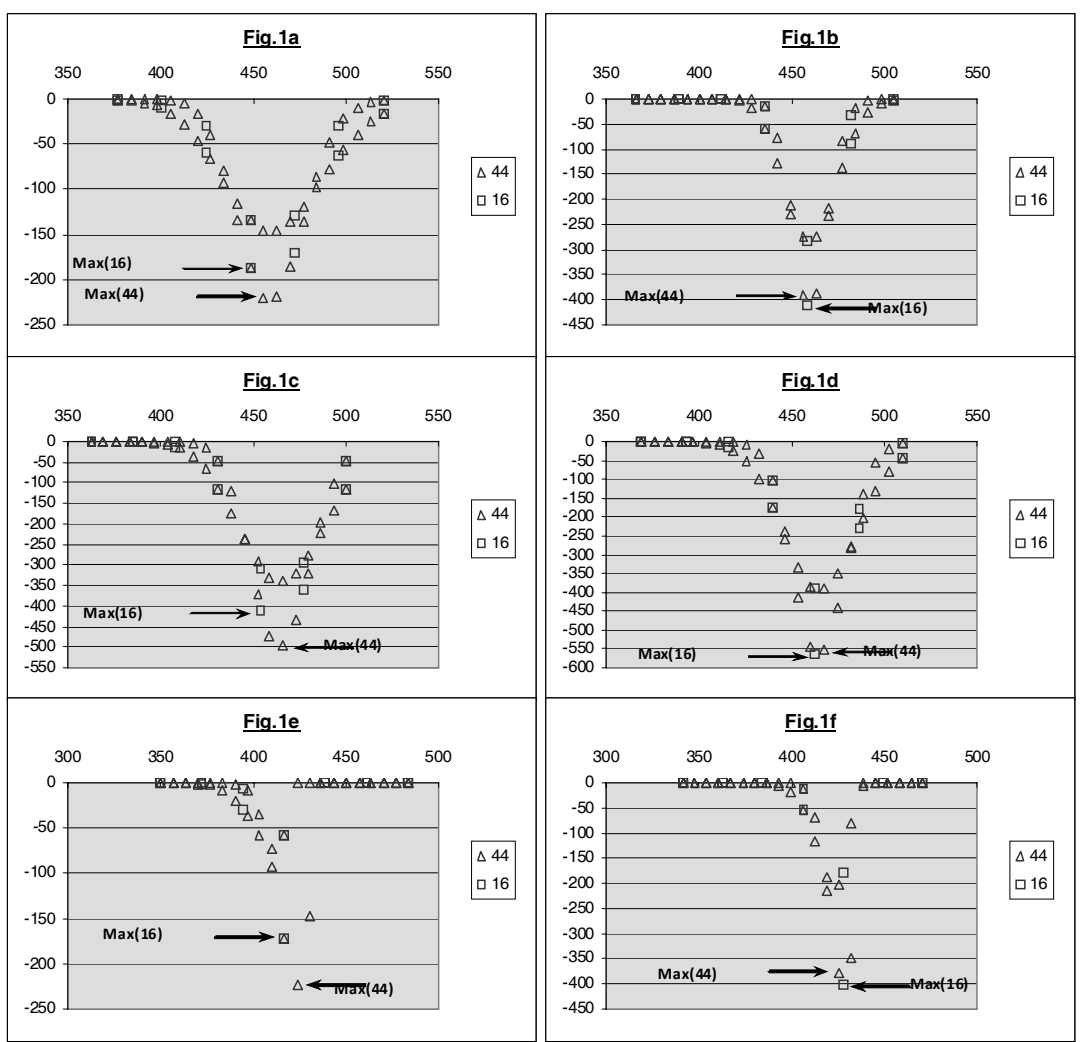

FIGURE 1.- Margin Requirements for Various Trading Strategies

Note: This table displays graphic representations of three trading strategies: "Butterfly" (fig. 1a, 1b), "Condor" (fig. 1c, 1d), and a combination of two calls written at strike price X, and one call purchased at strike price $Y$ where $Y>X$ (fig.1e, 1f). Figures 1a, 1b, and 1e offer examples in which SPAN-44 leads to higher margin requirements, while Figures 1b, 1d, and If display counter-examples where the reverse is true. Margin requirements for each method are indicated on each of the graphs.

The second simulation stage is based on transaction data collected during three months surrounding the system change date - May before the event, and July and August after the event. Daily calculations of margin levels and simulations of the various strike prices for each of the three strategies - at, above, and below the Index - add up to 530 simulations summarized in table 2 . The standard deviation used in calculating the options' margin is measured by the same method used by the TASE clearinghouse to measure the price volatility of the 
TABLE 2. Required Margins: SPAN-16 vs. SPAN-44

\begin{tabular}{cllcc}
\hline & & \multicolumn{3}{c}{ Cases of higher margin level: } \\
\hline \multirow{2}{*}{ Total } & & SPAN 44 & SPAN 16 & No Difference \\
\cline { 2 - 5 } By expiration date & Long portfolios & 217 & 18 & 93 \\
& Short portfolios & 185 & 17 & 53 \\
\cline { 2 - 5 } By extent of in- or & Out-of-the-money & 144 & 13 & 40 \\
out-of-the money & At-the-money & 127 & 7 & 20 \\
& In-the-money & 131 & 15 & 42 \\
\cline { 1 - 5 } By month & June 2001 & 127 & 8 & 31 \\
& July 2001 & 129 & 12 & 35 \\
& August 2001 & 146 & 15 & 28 \\
\hline
\end{tabular}

Note: This table presents the results of 530 simulations based on transaction data of the three months surrounding the system change-over date - June before the change, and July-August after the change. Margin levels and simulated striking prices are calculated for each trading day under three strategies: at the prevailing Index price, above that price, and below that price. The strategies are: "Butterfly," "Condor," and a combination of writing two calls at the striking price $\mathrm{X}$, and purchasing a call at striking price $\mathrm{Y}$ where $\mathrm{Y}>\mathrm{X}$.

underlying asset, the TASE-25 Index. This is done by calculating the average implied standard deviation of eight options, two call options and two put options of the next maturity date, and a similar set of four of the following maturity date. The mean implied standard deviation of the eight options is used by Exchange members to calculate the minimum margin required of traders. Note that the estimated standard deviation is independent of the price interval. Furthermore, the simulated fat tails are taken into account in the same manner as under the procedure followed by the Exchange, using the scenario-based SPAN method. This includes the allowance of a standard deviation that is twice the estimated value, the SPAN treatment of the Smile and Fat-Tails problems.

The first finding revealed by table 2 is that the switch to SPAN-44 leads to higher margin requirements in $76 \%$ of the cases. Requirements are lower only in $7 \%$ of the cases and unchanged in 18\%. In interpreting these results, one should bear in mind that the strategies used in this comparison were selected because of their expected strong influence on margin requirements. Given the equivalence of key scenarios, differences would be small or negligible had strategies like uncovered puts and calls, straddles or strangles were used instead. As such, the results presented overstate the typical difference between the two 
systems.

The second finding is that margin requirements set by SPAN-44 are, on average, $20 \%$ higher than those set by SPAN-16. Furthermore, in cases where the required margins of SPAN-44 are lower, the difference between the two margin levels averages only $3 \%$.

The third finding is that these results are not affected either by the month, or by the extent to which the options are in-the-money, out-of-the-money, or at-the-money.

\section{Empirical Findings}

\section{A. Data}

Data include all transactions in options and their underlying asset, the TA-25 Stock Index, during the month of June 2001, just before the system changeover date, and the month of July, just after that change. ${ }^{6}$ The overall sample consists of 3,029,877 put and call transactions, $1,525,703$ in June and 1,504,174 in July. For each day, the average implied standard deviation (ISD) and bid-ask spread (BA\%) reflect all transactions on that day, where:

$$
B A \%=100[(\text { Ask }- \text { Bid }) /(\text { Ask }+B i d) / 2]
$$

The effective bid-ask spread on shares comprising the TA-25 during June and July 2001 was calculated for each transaction just before it was conducted. In addition, daily data were collected on options' trading volume and number of open-interest positions. Interest rates are based on the yield-to-maturity of 3-month domestic T-Bills. Trading figures include all transactions for all possible expiration periods - one, two, and three months.

\section{B. Findings}

Increased trading efficiency. Table 3 summarizes the empirical test results. The first test estimates the effect of the switch from SPAN-16

6. The empirical tests were replicated using data from the extended period of two quarters (rather than two months) surrounding the changeover date. The results did not differ from those presented here. 
TABLE 3. The Impact of Switching from SPAN-16 to SPAN-44

\begin{tabular}{lccc}
\hline & $\begin{array}{c}\text { Period 1 - } \\
\text { Before Change }\end{array}$ & $\begin{array}{c}\text { Period 2 }- \\
\text { After Change }\end{array}$ & p-value \\
\cline { 1 - 2 } Trading Efficiency by: & 0.2513 & 0.1921 & 0.054 \\
100(S/S*-1) & & & \\
Liquidity by: & & & \\
\hline Bid-Ask Spread (BA\%) & 0.4549 & 0.4339 & 0.387 \\
TA-25 stocks & 3.2374 & 3.2325 & 0.851 \\
Options- entire sample & 2.5186 & 2.6327 & 0.624 \\
At-the-money options & 109,193 & 105,179 & 0.571 \\
Trading volume (No. of contracts) & 367,065 & 348,962 & 0.504 \\
Open interest (No. of contracts) & & & \\
Uncertainty by: & & & 0.000 \\
Implied standard deviation - TA-25 & 0.2456 & 0.2078 & 0.036 \\
Historical standard deviation - TA-25 & 0.2077 & 0.1954 &
\end{tabular}

Note: This table summarizes the effects of changing the margining system on trading volume, deviation from put-call parity, bid-ask spread (BA\%) on options and shares, number of open positions, implied standard deviation (ISD), and skewness of ISD distributions. Period 1 refers to trading data in the month preceding the change; Period 2 refers to the month immediately following the change. The historical daily standard deviation (HSD) is estimated using the GARCH $(1,1)$ model and based on daily data of the TA-25 stock Index from the beginning of April 2001 to the end of September 2001. Annual standard deviations are calculated by multiplying the daily figure by the square root of the number of trading days in 2001. The deviation from put-call parity prices (eq. 2) is calculated on the basis of at-the-money options as follows:

$$
\frac{S}{S^{*}}-1=\left|\frac{S}{C-P+X e^{-r T}}-1\right|
$$

In this table, the daily average of each parameter (22 observations in the month preceding the change, and 21 observations in the month following the change) is presented on the basis of average trading volume for each trading day. Daily averages are derived from intra-day data.

to SPAN-44 on trading efficiency. Efficiency is defined by the extent of price deviation from put-call parity. Deviation is measured by the absolute ratio between the TA-25 Price Index (S) and the equilibrium price predicted by the put-call parity $\left(\mathrm{S}^{*}\right)$ :

$$
\frac{S}{S *}-1=\left|\frac{S}{C-P+X e^{-r T}}-1\right|
$$


where $P$ and $C$ are the put and call prices, $X$ is the striking price, $T$ is the number of years to expiration, and $r$ is the annual yield to maturity of 3-month T-Bills. Only options traded within 30 seconds of each other were paired. Test results show that the increase in margining accuracy was associated with a decrease in the ratio $S / S^{*}-1$ from approximately $0.25 \%$ to $0.19 \%$, a change significant at the 0.05 level. This result establishes causality between margining accuracy and market efficiency consistent with the theoretical claim of Kose et al. (1997) and the expectations of those who implemented the margining change on the TASE.

No decrease of trading liquidity or volume. The observed positive effect on trading efficiency was not accompanied by decreased market liquidity, either in the option market or in the market for the stocks comprising the TA-25 Index - and this despite an increase in margin requirements. As those who modified the system hoped for, the change in margining did not adversely affect the trading volume or the number of open positions. Similarly, bid-ask spreads of the options and underlying assets remained unchanged. These findings are consistent with the proposition that, in and of themselves, increased margin requirements have contradictory effects on efficiency, especially if higher margins are not associated with a greater margining accuracy.

Decreased implied volatility. Despite unchanging trading volume and liquidity, the average implied standard deviation (ISD) fell by $3.8 \%$, from $24.56 \%$ to $20.77 \%$ (below 0.001 significance level). During the same period, the historical standard deviation (HSD) fell only by $1.2 \%$, from $20.78 \%$ to $19.54 \%$ (0.036 significance level). ${ }^{7}$ These findings support claims by Hardouvelis (1988) and Seguin (1990) that increased margin requirements have a positive effect on market stability as measured by a decrease in trading uncertainty. A possible explanation for the lower stock price volatility under SPAN-44 is a stricter, more

7. Historical daily standard deviation (HSD) was estimated using the GARCH $(1,1)$ model based on daily data of the TA-25 Index from the beginning of April to the end of September, 2001. Annual standard deviations were estimated on the basis of this model by multiplying the daily figure by the square root of the number of trading days in 2001. In addition, since the decision of the TASE to replace SPAN- 16 by SPAN- 44 was made on June7, 2001, the changes in ISDs and HSDs were estimated in May 2001 as well, two months before the system was changed. The results were essentially the same. On average, ISDs were approximately $24.76 \%$ in May compared with $24.56 \%$ in June. HSDs came out $21.81 \%$ in May compared with $20.77 \%$ in June. The insignificant difference $(0.17 \mathrm{p}$-value $)$ indicates that the change was felt only after it went into effect on July 1, 2001. 
frequent enforcement due to narrower margin intervals. The larger intervals of SPAN-16 offered greater opportunities for gaming the system.

Accurate pricing lowers risk. The final test is designed to determine the extent to which deviations from put-call parity, our measure of efficiency, is affected by the underlying stock Index price volatility. The following regression (based on data from June-July 2001) indicates a significant positive correlation between the two: ${ }^{8}$

$$
\begin{aligned}
& (S / S *-1)_{t}=-0.0954+1.3987 I S D_{t}+\varepsilon_{t}
\end{aligned}
$$

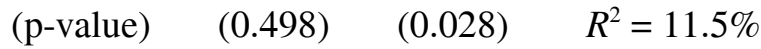

A similar result is obtained when the independent variable is controlled for the historical daily standard deviation of the stock Index over the same period $\left(\mathrm{HSD}_{1}\right)$ :

$$
\begin{gathered}
(S / S *-1)_{t}=0.1846+1.4596\left(I S D_{t}-H S D_{t}\right)+\varepsilon_{t} \\
\left(\begin{array}{lll}
\mathrm{p} \text {-value }) & (0.000) & (0.047)
\end{array}\right.
\end{gathered}
$$

These results suggest that improved accuracy in margining and the resulting increase in margin levels had a positive effect on the efficiency of option trading mainly through reduced uncertainty. Efficiency increased despite the apparent absence of improved liquidity in the options market or the market for the underlying stock Index.

\section{Summary and Conclusions}

The main conclusion of this paper is that increased margining accuracy is likely to improve the efficiency of option trading by lowering the probability of default without provoking a fully offsetting effect of decreased liquidity.

The required margin introduces a trade-off between two contradictory beneficial objectives, decreasing risk or increasing liquidity. The larger the required margin, the lower the credit risk. But

8. Here too, the results were essentially the same after extending the sampling period to the two quarters surrounding the date on which the change in the system was initiated. 
a larger margin is costlier for traders and leads to a thinner trade, which in turn decreases the options' liquidity. Conversely, liquidity can be increased by decreasing the required margin at the cost of a higher credit risk. The 16-scenario SPAN method developed in the U.S. and replicated in exchanges worldwide, including Israel, was designed to balance the marginal cost of extra risk against the marginal benefit of extra illiquidity.

The empirical tests reported in this paper are based on a unique initiative undertaken by the TASE to raise margining accuracy and efficiency by increasing the number of scenarios used in calculating default risk under its U.S.-style SPAN system. Efficiency is measured here, inter alia, by implied volatility, deviations from put-call parity, and liquidity. Supported by a large data set of option transactions and underlying stock price index surrounding this event, test results show that a switch from the standard 16-scenario to the 44-scenario SPAN led to increased efficiency by the first two criteria without decreasing efficiency by the third criterion, and this despite generally higher margin requirements.

The findings presented have important implications for current policy and future research. Consider the relationship between the volume of trade and the Bid-Ask spread. Previous empirical evidence shows that, other things held constant, an increase in volume would narrow the spread. This paper offers evidence of no change in volume following the switch from SPAN-16 to SPAN-44, suggesting that the narrower spread is caused by more efficient trading. The same can be said about the decrease in volatility based on the finding that the risk measured by implied standard deviation decreases more than the historical standard deviation. Since the former type of volatility is more influenced by trading errors, part of which due to credit risk, this evidence too suggests an increase in trading efficiency. Referring to the lack of symmetry in option trading, the literature cites the phenomenon of a Smile (skewness) where the implied standard deviation of options deep-in-the-money or deep-out-of-the-money is higher than that of options merely at-the-money. Findings presented here suggest that a margining method relying on more precisely defined scenarios, including extreme scenarios of double the standard deviation, which account for a Smile or skewness, is likely to promote trading efficiency by pricing credit risk more accurately without adversely affect liquidity.

Accepted by: Prof. P. Theodossiou, Editor-in-Chief, November 2009 


\section{Appendix}

TABLE A1. The Scenarios under SPAN-16 (Replaced July 1, 2001)

\begin{tabular}{llc}
\hline Scenario No. & Scenario Index & $\begin{array}{c}\text { Scenario } \\
\text { Standard Deviation }\end{array}$ \\
\hline 1. & $\mathrm{~S}$ & $\sigma+\alpha$ \\
2. & $\mathrm{S}$ & $\sigma-\alpha$ \\
3. & $\mathrm{~S}[1+(1 / 3) \mathrm{M}]$ & $\sigma+\alpha$ \\
4. & $\mathrm{~S}[1+(1 / 3) \mathrm{M}]$ & $\sigma-\alpha$ \\
5. & $\mathrm{~S}[1-(1 / 3) \mathrm{M}]$ & $\sigma+\alpha$ \\
6. & $\mathrm{~S}[1-(1 / 3) \mathrm{M}]$ & $\sigma-\alpha$ \\
7. & $\mathrm{~S}[1+(2 / 3) \mathrm{M}]$ & $\sigma+\alpha$ \\
8. & $\mathrm{~S}[1+(2 / 3) \mathrm{M}]$ & $\sigma-\alpha$ \\
9. & $\mathrm{~S}[1-(2 / 3) \mathrm{M}]$ & $\sigma+\alpha$ \\
10. & $\mathrm{~S}[1-(2 / 3) \mathrm{M}]$ & $\sigma-\alpha$ \\
11. & $\mathrm{~S}(1+\mathrm{M})$ & $\sigma+\alpha$ \\
12. & $\mathrm{~S}(1+\mathrm{M})$ & $\sigma-\alpha$ \\
13. & $\mathrm{~S}(1-\mathrm{M})$ & $\sigma+\alpha$ \\
14. & $\mathrm{~S}(1-\mathrm{M})$ & $\sigma-\alpha$ \\
$1 .^{+}$ & $\mathrm{S}(1+2 \mathrm{M})$ & $2 \sigma$ \\
$16 .+$ & $\mathrm{S}(1-2 \mathrm{M})$ & $2 \sigma$ \\
\hline
\end{tabular}

Note: In this table, S stands for the TA-25 stock price Index and M for its volatility coefficient. Sigma denotes the annual standard deviation, and a the volatility coefficient of the standard deviation as set by the TASE. During the sample period, $M=0.16$ and $\alpha=$ $(1 / 5) \sigma .{ }^{+}$Extreme scenarios. 
TABLE A2. The Scenarios under SPAN-44 (Beginning July 1, 2001)

\begin{tabular}{|c|c|c|}
\hline Scenario No. & Scenario Index & $\begin{array}{c}\text { Scenario } \\
\text { Standard Deviation }\end{array}$ \\
\hline 1. & S & $\sigma+\alpha$ \\
\hline 2. & $\mathrm{~S}$ & $\sigma-\alpha$ \\
\hline 3. & $\mathrm{~S}(1+0.1 \mathrm{M})$ & $\sigma+\alpha$ \\
\hline 4. & $\mathrm{~S}(1+0.1 \mathrm{M})$ & $\sigma-\alpha$ \\
\hline 5. & $\mathrm{~S}(1-0.1 \mathrm{M})$ & $\sigma+\alpha$ \\
\hline 6. & $\mathrm{~S}(1-0.1 \mathrm{M})$ & $\sigma-\alpha$ \\
\hline 7. & $\mathrm{~S}(1+0.2 \mathrm{M})$ & $\sigma+\alpha$ \\
\hline 8. & $\mathrm{~S}(1+0.2 \mathrm{M})$ & $\sigma-\alpha$ \\
\hline 9. & $\mathrm{~S}(1-0.2 \mathrm{M})$ & $\sigma+\alpha$ \\
\hline 10. & $\mathrm{~S}(1-0.2 \mathrm{M})$ & $\sigma-\alpha$ \\
\hline 11. & $\mathrm{~S}(1+0.3 \mathrm{M})$ & $\sigma+\alpha$ \\
\hline 12. & $\mathrm{~S}(1+0.3 \mathrm{M})$ & $\sigma-\alpha$ \\
\hline 13. & $\mathrm{~S}(1-0.3 \mathrm{M})$ & $\sigma+\alpha$ \\
\hline 14. & $\mathrm{~S}(1-0.3 \mathrm{M})$ & $\sigma-\alpha$ \\
\hline 15. & $\mathrm{~S}(1+0.4 \mathrm{M})$ & $\sigma+\alpha$ \\
\hline 16. & $\mathrm{~S}(1+0.4 \mathrm{M})$ & $\sigma-\alpha$ \\
\hline 17. & $\mathrm{~S}(1-0.4 \mathrm{M})$ & $\sigma+\alpha$ \\
\hline 18. & $\mathrm{~S}(1-0.4 \mathrm{M})$ & $\sigma-\alpha$ \\
\hline 19. & $\mathrm{~S}(1+0.5 \mathrm{M})$ & $\sigma+\alpha$ \\
\hline 20. & $\mathrm{~S}(1+0.5 \mathrm{M})$ & $\sigma-\alpha$ \\
\hline 21. & $\mathrm{~S}(1-0.5 \mathrm{M})$ & $\sigma+\alpha$ \\
\hline 22. & $\mathrm{~S}(1-0.5 \mathrm{M})$ & $\sigma-\alpha$ \\
\hline 23. & $\mathrm{~S}(1+0.6 \mathrm{M})$ & $\sigma+\alpha$ \\
\hline 24. & $\mathrm{~S}(1+0.6 \mathrm{M})$ & $\sigma-\alpha$ \\
\hline 25. & $S(1-0.6 \mathrm{M})$ & $\sigma+\alpha$ \\
\hline 26. & $\mathrm{~S}(1-0.6 \mathrm{M})$ & $\sigma-\alpha$ \\
\hline 27. & $\mathrm{~S}(1+0.7 \mathrm{M})$ & $\sigma+\alpha$ \\
\hline 28. & $\mathrm{~S}(1+0.7 \mathrm{M})$ & $\sigma-\alpha$ \\
\hline 29. & $\mathrm{~S}(1-0.7 \mathrm{M})$ & $\sigma+\alpha$ \\
\hline 30. & $\mathrm{~S}(1-0.7 \mathrm{M})$ & $\sigma-\alpha$ \\
\hline 31. & $\mathrm{~S}(1+0.8 \mathrm{M})$ & $\sigma+\alpha$ \\
\hline 32. & $\mathrm{~S}(1+0.8 \mathrm{M})$ & $\sigma-\alpha$ \\
\hline 33. & $\mathrm{~S}(1-0.8 \mathrm{M})$ & $\sigma+\alpha$ \\
\hline 34. & $\mathrm{~S}(1-0.8 \mathrm{M})$ & $\sigma-\alpha$ \\
\hline 35. & $\mathrm{~S}(1+0.9 \mathrm{M})$ & $\sigma+\alpha$ \\
\hline 36. & $\mathrm{~S}(1+0.9 \mathrm{M})$ & $\sigma-\alpha$ \\
\hline 37. & $\mathrm{~S}(1-0.9 \mathrm{M})$ & $\sigma+\alpha$ \\
\hline 38. & $\mathrm{~S}(1-0.9 \mathrm{M})$ & $\sigma-\alpha$ \\
\hline 39. & $\mathrm{~S}(1+\mathrm{M})$ & $\sigma+\alpha$ \\
\hline 40. & $\mathrm{~S}(1+\mathrm{M})$ & $\sigma-\alpha$ \\
\hline 41. & $\mathrm{~S}(1-\mathrm{M})$ & $\sigma+\alpha$ \\
\hline 42. & $\mathrm{~S}(1-\mathrm{M})$ & $\sigma-\alpha$ \\
\hline
\end{tabular}

( Continued) 
TABLE A2. (Continued)

\begin{tabular}{lcc}
\hline Scenario No. & Scenario Index & $\begin{array}{c}\text { Scenario } \\
\text { Standard Deviation }\end{array}$ \\
\hline $43 .^{+}$ & $\mathrm{S}(1+2 \mathrm{M})$ & $2 \sigma$ \\
$44 .^{+}$ & $\mathrm{S}(1-2 \mathrm{M})$ & $2 \sigma$ \\
\hline
\end{tabular}

Note: In this table, S stands for the TA-25 stock price Index and $\mathrm{M}$ for its volatility coefficient. Sigma denotes the annual standard deviation, and a the volatility coefficient of the standard deviation as set by the TASE. During the sample period, $M=0.16$ and $\alpha=$ $(1 / 5) \sigma .{ }^{+}$Extreme scenarios.

\section{References}

Black, F., and Scholes, M. 1973. The pricing of options and corporate liabilities. Journal of Political Economy 81:637-659.

Chowdhry, B., and Nanda, V. 1998. Leverage and market stability: The role of margin rules and price limits. Journal of Business 71:179-210.

Day, T., and Lewis, C. 1997. Margin adequacy in futures markets. Memo, Owen Graduate School of Management, Vanderbilt University.

Dutt, H. R., and Wein, I. L. 2003. Revisiting the empirical estimation of the effect of margin changes on futures trading volume. The Journal of Futures Markets 6:561-576.

Fenn, G., and Kupiec, P. 1993. Prudential margin policy in a futures-style settlement system. The Journal of Futures Markets 13:389-408.

Figlewski, S. 1984. Margins and market integrity: Margin setting for stock index futures and options. The Journal of Futures Markets 4:385-416.

Fishe, R. P., and Goldberg, L. G. 1986. The effects of margins on trading in futures markets. The Journal of Futures Markets 6: 261-271.

Fishe, R. P.; Goldberg, L. G.; Gosnell, T.; and Sinha S. 1990. Margin requirements in futures markets: Their relationship to price volatility. The Journal of Futures Markets 10:541-554.

Garbade, K. D. 1986. Federal Reserve margin requirements: A regulatory initiative to inhibit speculative bubbles. In P. Wachtel (ed). Crises in Economics and Financial Structure. Lexington, Mass.: Lexington Books.

Gay, G.; Hunter, W.; and Kolb, R. 1986. A comparative analysis of futures contract margins. The Journal of Futures Markets 6:307-324.

Hardouvelis, G. 1988. Margin requirements and stock market volatility. Quarterly Review, Federal Reserve Bank of New York (Summer).

Hardouvelis, G. 1990. Margin requirements, volatility, and the transitory component of stock prices. American Economic Review 80:736-763.

Hardouvelis, G., and Kim, D. 1995. Margin requirements, price fluctuations, and market participation in metal futures. Journal of Money, Credit and 
Banking 27:659-671.

Hartzmak, M. L. 1986. The effects of changing margin levels on futures market activity, the composition of traders in the market, and price performances. Journal of Business 2 (2):147-180.

Hsieh, D., and Miller, M. 1990. Margin regulation and stock market volatility. Journal of Finance 45:3-30.

Kose, J.; Kotichia, A.; Narayanan, R.; and Subrahmanyam, M. 1997. Margin rules, informed trading in derivatives and price dynamics. Working Paper, Stern School of Business.

Kupiec, P. 1989. Initial margin requirements and stock return volatility: Another look. Journal of Financial Services Research 3:189-202.

Kupiec, P. 1993. Futures margins and stock price volatility: Is there any link? The Journal of Futures Markets 13:677-692.

Kupiec, P. 1994. The performance of S\&P 500 Futures product margins under the SPAN margining system," The Journal of Futures Markets 14:789-811.

Kupiec, P. 1998. Margin requirements, volatility, and market integrity: What have we learned since the crash?" Journal of Financial Services Research 13:231-256.

Kupiec, P., and White, P. 1996. "Regulatory competition and the efficiency of alternative derivative product margining systems. The Journal of Futures Markets 16:943-969.

Moser, J. 1992. Determining margins for futures contracts: The role of private interests and the relevance of excess volatility. Economic Perspectives. Federal Reserve Bank of Chicago, March-April, 2-18.

Salinger, M. 1989. Stock market margin requirements and volatility: Implications for regulation of stock index futures. Journal of Financial Services Research 3:121-138.

Schwert, G. W. 1989. Margin requirements and stock volatility. Journal of Financial Services Research 3:153-164.

Seguin, P. 1990. Stock volatility and margin trading. Journal of Monetary Economics 26:101-121.

Seguin, P., and Jarrell, G. 1993. The irrelevance of margin: Evidence from the crash of 87. Journal of Finance 48:1457-1473.

Sofianos, G. 1988. Margin requirements of equity instruments. Quarterly Review 13:47-60, Federal Reserve Bank of New York. 